\title{
Identifying the critical factors that influence intraocular pressure using an automated regression tree
}

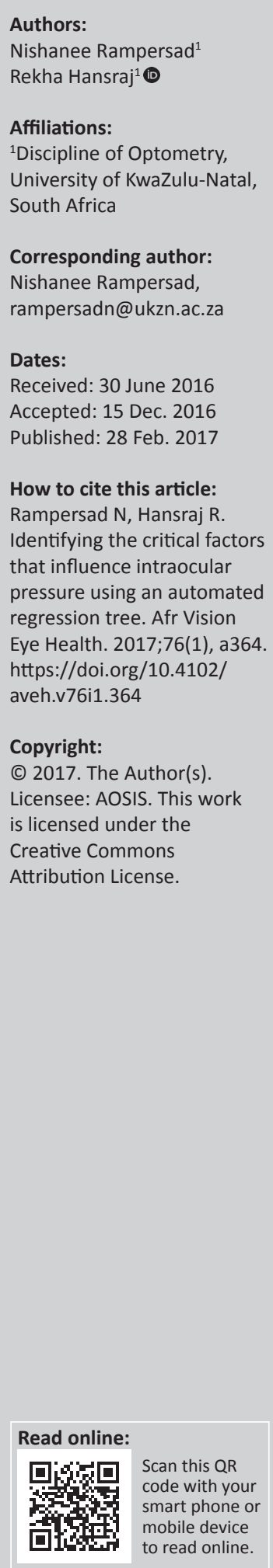

Background: Assessment of intraocular pressure (IOP) is an important test in glaucoma. In addition, anterior segment variables may be useful in screening for glaucoma risk. Studies have investigated the associations between IOP and anterior segment variables using traditional statistical methods. The classification and regression tree (CART) method provides another dimension to detect important variables in a relationship automatically.

Aim: To identify the critical factors that influence IOP using a regression tree.

Methods: A quantitative cross-sectional research design was used. Anterior segment variables were measured in 700 participants using the iVue100 optical coherence tomographer, Oculus Keratograph and Nidek US-500 ultrasonographer. A Goldmann applanation tonometer was used to measure IOP. Data from only the right eyes were analysed because of high levels of interocular symmetry. A regression tree model was generated with the CART method and Pearson's correlation coefficients were used to assess the relationships between the ocular variables.

Results: The mean IOP for the entire sample was $14.63 \mathrm{mmHg} \pm 2.40 \mathrm{mmHg}$. The CART method selected three anterior segment variables in the regression tree model. Central corneal thickness was the most important variable with a cut-off value of $527 \mu \mathrm{m}$. The other important variables included average paracentral corneal thickness and axial anterior chamber depth. Corneal thickness measurements increased towards the periphery and were significantly correlated with IOP $(r \geq 0.50, p \leq 0.001)$.

Conclusion: The CART method identified the anterior segment variables that influenced IOP. Understanding the relationship between IOP and anterior segment variables may help to clinically identify patients with ocular risk factors associated with elevated IOPs.

\section{Introduction}

Glaucoma is an optic neuropathy that sometimes results in irreversible blindness. ${ }^{1}$ After cataracts, glaucoma is the second most prevalent cause of global blindness, ${ }^{2}$ and it is estimated that almost 80 million people worldwide will be affected by this optic neuropathy by the year $2020 .{ }^{3}$ Because of the high prevalence of this ocular disease, the economic and social implications of glaucoma have been outlined in recent studies. ${ }^{4,5}$ In Africa, primary open-angle glaucoma (POAG) is more prevalent than primary-angle closure glaucoma, and over the next 4 years, the prevalence of POAG in Africa is projected to increase by $23 \%$ corresponding to an increase from 6.2 million to 8.0 million affected individuals. ${ }^{3}$ Consequently, in Africa, there have been recommendations to incorporate glaucoma screening procedures into routine eye examinations as well as implement glaucoma blindness control programs. ${ }^{6,7}$

The assessment of intraocular pressure (IOP) is a fundamental clinical test used for the screening, diagnosis and management of glaucoma. ${ }^{1,8}$ IOP is still considered as an important risk factor for glaucoma, ${ }^{1,9}$ but previous studies have reported that other ocular anterior segment variables are also useful in screening for individuals at risk for glaucoma. ${ }^{10,11,12,13}$ For example, the Ocular Hypertension Treatment Study highlighted the importance of central corneal thickness (CCT) in evaluating risk for POAG. ${ }^{10}$ Some studies have indicated that other anterior chamber variables (such as depth and angle width) may be useful for evaluating risk for developing angle closure glaucoma. ${ }^{12,13,14}$ As a result, the relationship between IOP and anterior segment ocular variables has been investigated in both population-based ${ }^{15,16,17}$ and clinic-based ${ }^{18,19,20}$ studies. 
Investigating the relationship between IOP and anterior segment ocular variables may be useful for better understanding the association between these ocular variables and IOP. ${ }^{8}$ This knowledge may help to clinically identify patients with ocular risk factors associated with elevated IOPs. ${ }^{21}$ The association between IOP and CCT is well known with several studies ${ }^{22,23,24}$ noting higher IOP measurements in eyes with thicker CCT measurements. In contrast, the literature related to IOP and corneal curvature is inconsistent, with some studies ${ }^{20,25}$ reporting no association while other studies $^{15,16,19,21,26}$ reported significantly higher IOPs in eyes with steeper corneal curvatures. No associations have been found between IOP and corneal diameter ${ }^{27}$ or anterior chamber angle (ACA) variables..$^{15,28,29}$

The majority of the studies have used traditional statistical methods, such as correlation and regression analyses, to assess the relationship between IOP and anterior segment ocular variables. $15,16,17,19$ However, these statistical methods may result in erroneous conclusions especially when their inherent assumptions are misunderstood and/or results are inaccurately interpreted..$^{30,31}$ In addition, both correlation and linear regression analyses only show linear relationships and may omit the more complex relationships that exist when you have more than two variables. ${ }^{32,33}$ Not surprisingly therefore, several researchers have cautioned against misinterpreting a large significant correlation between two variables as a causal relationship between the two variables of interest. ${ }^{30,32,33}$

In the absence of any ocular abnormalities, ocular variables for the right and left eye of the same individual are related. ${ }^{34,35}$ Furthermore, the different ocular variables, within the same eye, may be inherently related and correlated. The related nature of clinical variables, from a particular biological system, is not exclusive to optometry and has also been shown in dental and medical research. ${ }^{31,36}$ Multiple regression analysis is often used to make predictions and suggest explanations for a dependent variable when there are more than two independent variables. ${ }^{36}$ When clinical variables, which are used in multiple regression analysis, are highly correlated, it results in mathematical coupling and collinearity. ${ }^{36,37}$ Collinearity can distort the relationship between two ocular variables especially when both variables of interest are highly correlated with another ocular variable. ${ }^{30}$ Therefore, a statistical method that overcomes some of these challenges is preferred for assessing the relationship between IOP and multiple anterior segment ocular variables.

Classification and regression tree (CART) is an analysis method that is able to detect which variables are important in a relationship or model. ${ }^{38,39}$ This method is useful for large data sets that contain multiple variables that may have nonlinear relationships. ${ }^{40,41}$ The CART method has several advantages including that it can be used with skewed data, requires minimal input from the researcher because of an automatic independent variable selection process, is able to handle collinearity together with missing variables and displays information in a way that is simple to interpret even for individuals with limited statistical backgrounds. ${ }^{41,42,43}$
The CART method generates a regression tree model when a dependent variable is predicted based on multiple independent variables. ${ }^{44}$ In a regression tree model, the dependent variable is continuous while the independent variables may be either continuous or categorical. ${ }^{41,43}$ Furthermore, regression tree models are simple to present and resemble the process used in clinical reasoning as they are generated based on a logical sequence of 'if-then' statements or decision rules. ${ }^{44}$ For this reason, the CART method is said to have greater practical relevance in clinical situations. ${ }^{42}$ To this end, several studies have produced regression trees, using the CART method, for clinical conditions including myocardial infarction, ${ }^{45}$ dental caries $^{46}{ }^{46}$ asthma, ${ }^{47}$ dry eye ${ }^{48}$ keratoconus $^{49}$ and low vision rehabilitation. ${ }^{50}$

Graphically, regression tree models consist of a single node (call the root) and consecutive internal nodes that are defined by a characteristic-independent variable and its respective cut-off value that splits the data into two sub-groups..$^{40,41,42} \mathrm{At}$ each internal node, the CART method iteratively evaluates all the independent variables and automatically selects the variable and its cut-off value that is most efficient in splitting the data into two sub-groups containing similar values for the dependent variable. ${ }^{41,43,51}$ Consequently, regression tree models are generated using binary recursive partitioning because of the two-way split at each internal node. ${ }^{42,44}$ The process of splitting the sub-groups is continued until the data cannot be split any further resulting in terminal nodes. ${ }^{40}$ The root node contains all cases in the data while each terminal node depicts the number of cases (from the data) and the mean value of the dependent variable located within that branch. ${ }^{40}$

Regression tree models that consist of too many branches are unnecessarily large and complex. ${ }^{40}$ Such a model is likely to 'overfit' the data resulting in poor generalisability to new data. ${ }^{40,42,49}$ Thus, a pruning process is applied to the initial large regression tree model, which removes internal nodes that are considered 'noise' and contribute no predictive power to the regression tree model. ${ }^{51}$ Consequently, pruning often results in a smaller regression tree model..$^{40}$ Furthermore, pruned regression trees have better predictive accuracy because they go through a cross-validation procedure to select the optimal-sized tree. ${ }^{43}$

The aim of this study was to identify the critical anterior segment ocular variables that influence IOP using an automated regression tree. By using the CART method, it is hoped that the statistical analysis would validate which anterior segment variables have the most influence on IOP. In this way, the CART method may also suggest mechanisms of anterior segment variables affecting IOP that may not have been investigated previously.

\section{Methodology}

The study employed a quantitative cross-sectional research design and was conducted at the University of KwaZuluNatal eye clinic. The study population consisted of black 
and Indian students from the University of KwaZulu-Natal. Two-stage random sampling was used to recruit 700 (350 black and 350 Indian) participants aged between 17 and 30 years. Participants were tested using screening procedures to determine their eligibility in accordance with the study inclusion criteria. The screening procedures included case history (ocular and medical), logarithm of the minimum angle of resolution (LogMAR) distance visual acuity, autorefraction (using the Nidek AR-1) and subjective refraction, slit-lamp biomicroscopy, ophthalmoscopy and non-contact tonometry (via the Nidek NT530P). Participants were excluded with visual acuity (unaided or best corrected) worse than $0 \mathrm{LogMAR}$, IOP greater than $21 \mathrm{mmHg}$, contact lens wear in the past 3 weeks or previous history of ocular trauma and/or surgery, systemic and/or ocular diseases and currently on medication. Thereafter, data collection procedures were performed on eligible participants.

Corneal thickness and ACA variables such as the angleopening distance taken at $500 \mu \mathrm{m}$ (AOD500) and trabeculariris angle (TIA) were scanned and measured using the Optovue iVue100 optical coherence tomographer (OCT). This Fourier-domain OCT is capable of generating $25000 \mathrm{~A}$-scans per second with an axial and transverse resolution of $5 \mu \mathrm{m}$ and $15 \mu \mathrm{m}$, respectively. ${ }^{52}$ A pre-programmed algorithm in the iVue100 OCT defines the corneal epithelium and endothelium as the anterior and posterior boundaries, respectively. ${ }^{52}$ The corneal thickness is automatically determined as the distance between these two boundaries. The AOD500 and TIA were measured using the inbuilt angle tools in the iVue100 OCT. As per the manufacturer's recommendations, ${ }^{52}$ repeat scans were taken when the scan was labelled as poor on the laptop screen or had a scan quality index of $<27$. During scanning, the real-time images of the participant's eye with either the cornea or ACA were monitored on the laptop screen.

The corneal pachymetry scan protocol which consists of eight radial $(6 \mathrm{~mm})$ line scans of $1024 \mathrm{~A}$-scans each was used to measure corneal thickness. ${ }^{52}$ During corneal scanning, participants were instructed to look at the internal fixation target. The corneal pachymetry scan protocol displays the average corneal thickness in a $6 \mathrm{~mm} \times 6 \mathrm{~mm}$ pachymetry map (Figure 1). This pachymetry map (Figure 1) is divided by rings into three corneal sections (central, paracentral and peripheral). CCT is defined as the average thickness in the central 2-mm ring. The middle and outermost rings, of 5-mm and 6-mm diameter, denote the paracentral and peripheral corneal sections, respectively. The paracentral and peripheral cornea are further divided into eight zones (superior, superior-temporal, temporal, inferior-temporal, inferior, inferior-nasal, nasal and superior-nasal). The average thickness in the central, paracentral and peripheral corneal sections (17 zones) are displayed in the corneal pachymetry map using a false-colour display (Figure 1). In this study, the average paracentral corneal thickness (ParaCT) and average

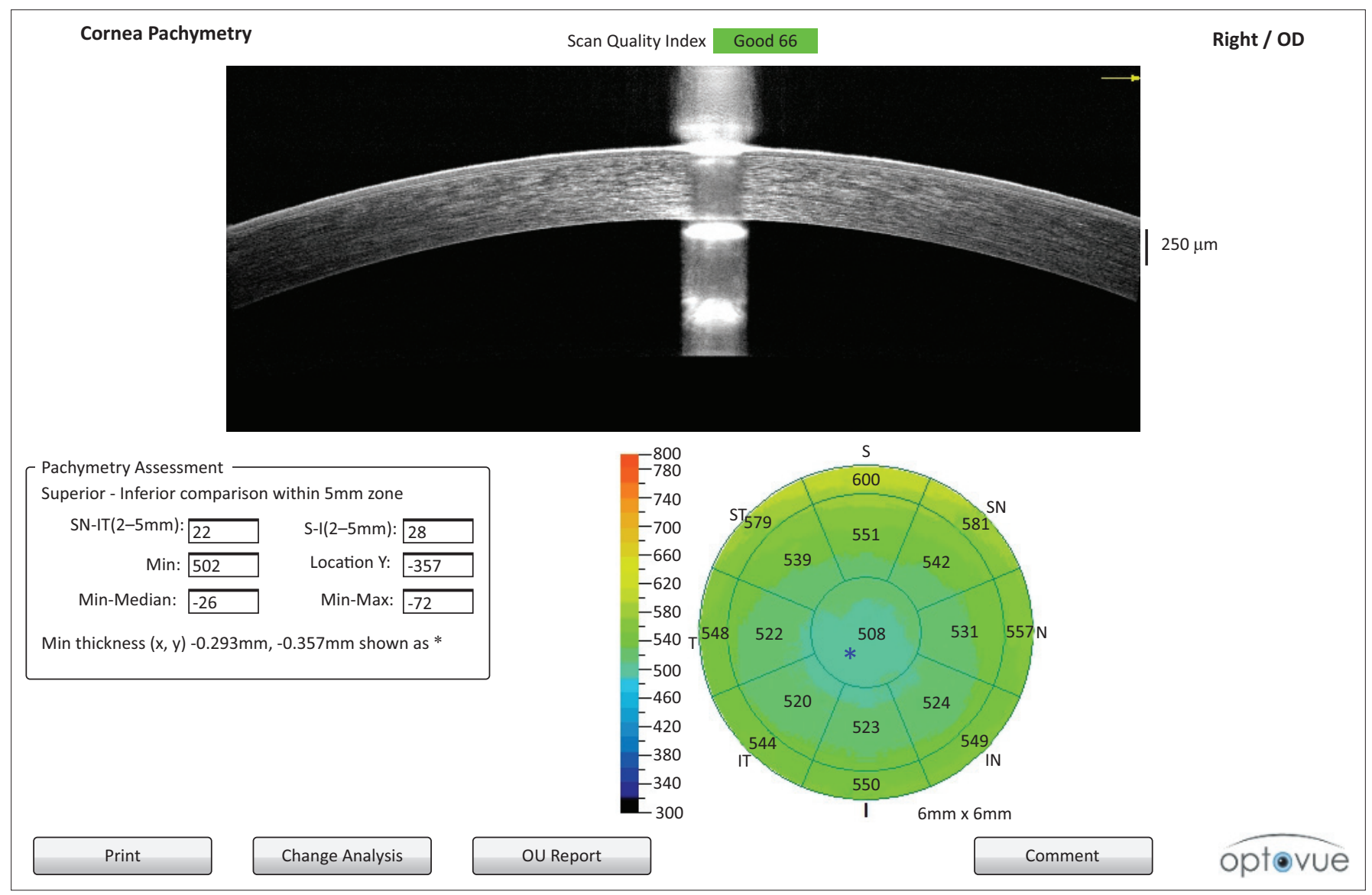

FIGURE 1: Corneal pachymetry map showing the mean corneal thickness in the centre and each zone in the paracentral and peripheral cornea. 
peripheral corneal thickness (PeriCT) were computed as the average of the eight zones therein.

The cornea angle scan protocol was used to image and measure the ACA variables (AOD500 and TIA). The cornea angle scan consists of a single $(5 \mathrm{~mm})$ line scan of 1024 A-scans. ${ }^{52}$ The ACAs in the horizontal meridian (nasal and temporal) were measured as they are unlikely to be distorted by the eyelids ${ }^{53}$ and have better repeatability than ACAs in the vertical meridian. ${ }^{54}$ During cornea angle scanning, participants were instructed to look at the inbuilt external fixation target mounted on the side of the iVue100 OCT while the line scan was centred on the limbus (nasal or temporal). This ensured that the limbal surface was aligned to the OCT light beam and that the cornea appeared flattened to minimise diffraction and distortion. ${ }^{53,55}$ The cornea angle scan protocol displays the ACA analysis using a gray-scale display (Figure 2).

The ACA variables (AOD500 and TIA) were determined using the method described by Pavlin et $a .^{56}$ and subsequently used in several other studies. ${ }^{28,57,58}$ This method involved identifying ACA landmarks including the angle recess, scleral spur, point on the trabecular meshwork $500 \mu \mathrm{m}$ anterior to the scleral spur and the corresponding perpendicular point on the iris surface. ${ }^{55,59}$ The AOD500 represents the linear distance (in $\mu \mathrm{m}$ ) from the point on the trabecular meshwork to the perpendicular point on the iris surface $^{55}$ (Figure 2). In this study, the average AOD500 was computed as the average of the nasal and temporal AOD500 measurements. The TIA represents the angular measurement (in degrees) of the triangle formed by the angle recess, point on the trabecular meshwork and the perpendicular point on the iris surface ${ }^{55}$ (Figure 2). In this study, the average TIA was computed as the average of the nasal and temporal TIA measurements.

Previous studies have reported that OCT devices have good repeatability and reproducibility for measuring corneal thickness ${ }^{60,61}$ and ACA variables. ${ }^{59,62}$ Because the ACA variables (AOD500 and TIA) were measured manually, the researcher re-measured the ACA variables on 10 randomly selected participants after data collection. The re-measured ACA measurements showed good agreement with the original measurements (intraclass correlation coefficients $\geq 0.965)$. Corneal curvature and diameter were measured using the Oculus Keratograph, which is considered reliable and has been used in previous studies. ${ }^{63,64}$ Anterior chamber depth (ACD) was assessed using the Nidek US-500 A-scan ultrasound device, which has been used in previous studies to measure axial biometry. ${ }^{65}$ The IOP was measured with a Goldmann applanation tonometer, which is regarded as the gold standard for measuring IOP. ${ }^{66}$ To promote standardisation, all measurements were performed by one researcher and three measurements per variable were recorded and averages computed.

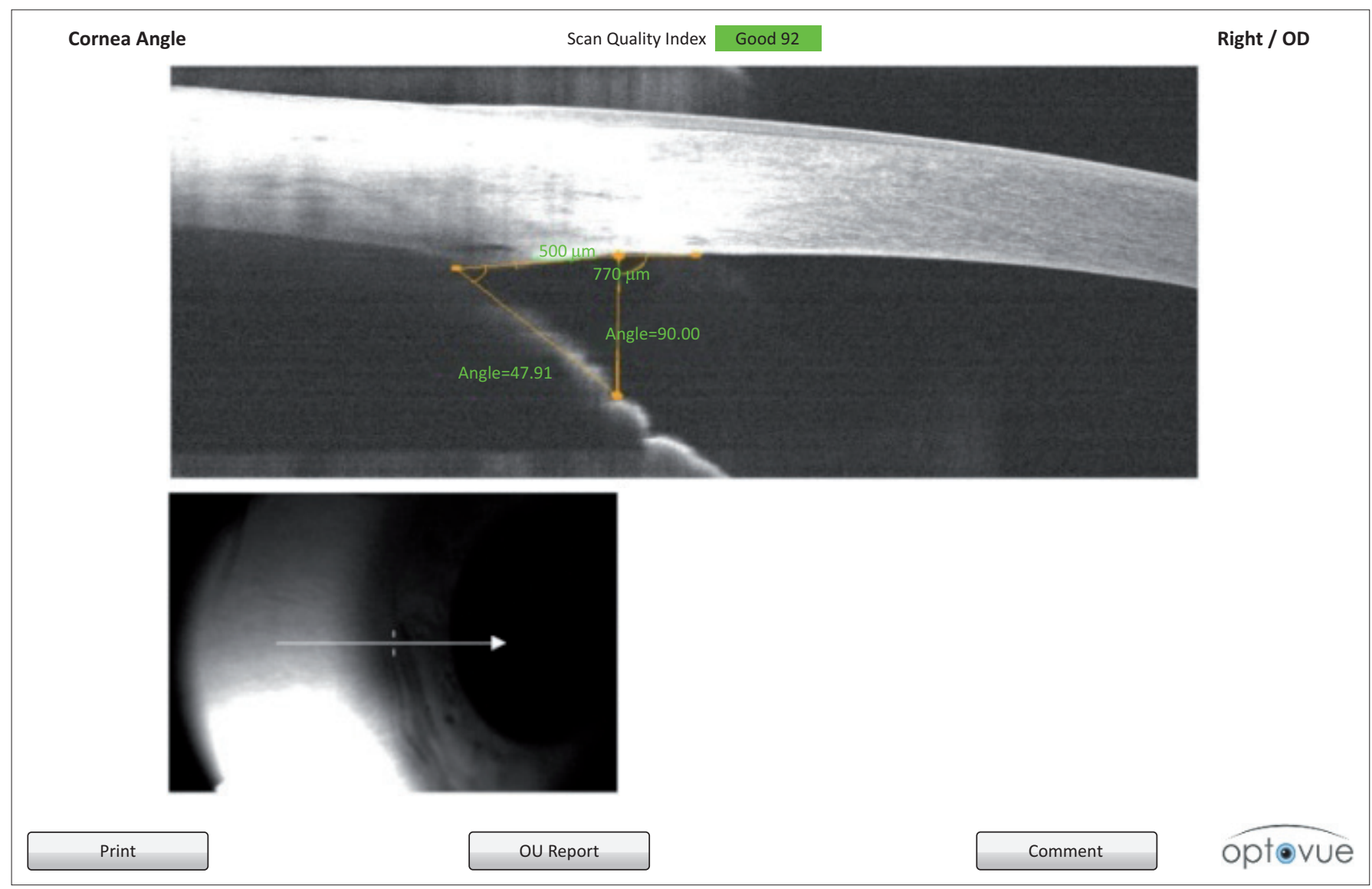

FIGURE 2: Cornea angle analysis showing the ACA variables (AOD500 and TIA). 
Data were captured and analysed with two software packages namely the Statistical Package for Social Sciences and the $R$ Package. The Shapiro-Wilk's test and graphical inspection of histograms were used to assess the distributions of the data concerned. Descriptive statistics included means and standard deviations. Interocular symmetry and the reproducibility of ACA measurements were assessed using intraclass correlation coefficients. ${ }^{35}$ Dependent-sample $t$-tests were used to assess differences in corneal thickness measurements in the different corneal sections. Pearson's correlation coefficient was used to assess the relationship between study variables. The RPART function in the R Package was used to generate the regression tree models. Eleven independent variables were entered into the CART method including three demographic covariates (gender, age and race) and eight anterior segment ocular variables (CCT, average ParaCT, average PeriCT, corneal diameter, average corneal curvature, axial ACD, average AOD500 and average TIA). The study adopted a 95\% significance level where $p \leq 0.05$ were considered statistically significant.

\section{Ethical considerations}

Ethical approval for the study (reference number BE 189/12) was obtained from the Biomedical Research and Ethics Committee of the University of KwaZulu-Natal. All participants provided written informed consent after a discussion of the nature of the study procedures involved. All ethical guidelines, in accordance with the Declaration of Helsinki, were adhered to during the study.

\section{Results}

The study sample included 700 participants with an equal distribution of male $(n=350)$ and female $(n=350)$ participants. Furthermore, $50 \%$ of the sample consisted of South African blacks and the other 50\% were South African Indians. The participants' ages ranged between 17 and 29 years, with a mean of $20.42 \pm 1.80$ years. The preliminary analysis showed that anterior segment ocular variables of the right and left eyes were similar (intraclass correlation coefficients $\geq 0.880$ ). The IOP measurements of the right and left eye were also similar with a mean difference of only $0.27 \mathrm{mmHg}$ and intraclass correlation coefficient of 0.884 . Therefore, data from only the right eyes of the 700 participants were analysed because of the high levels of interocular symmetry.

Table 1 shows the ocular characteristics of the study participants. The mean IOP for the entire sample was $14.63 \mathrm{mmHg} \pm 2.40 \mathrm{mmHg}$ (range, $10 \mathrm{mmHg}-21 \mathrm{mmHg}$ ). The CCT was significantly thinner than both the average ParaCT (mean difference of $19.15 \mu \mathrm{m}, p \leq 0.001$ ) and average PeriCT (mean difference of $44.91 \mu \mathrm{m}, p \leq 0.001$ ). The IOP was significantly correlated $(r \geq 0.50, p \leq 0.001)$ with corneal thickness measurements in all three sections (central, paracentral and peripheral). Even though IOP was significantly correlated with corneal diameter, axial ACD and average AOD500, the correlation coefficients noted were weak $(r \leq 0.15, p \leq 0.016)$. There was no association between IOP and average corneal curvature $(p=0.689)$ or TIA $(p=0.858)$.
TABLE 1: Means and standard deviations for ocular characteristics.

\begin{tabular}{lc}
\hline Characteristic & Mean \pm s.d. \\
\hline IOP $(\mathrm{mmHg})$ & $14.63 \pm 2.40$ \\
$\mathrm{CCT}(\mu \mathrm{m})$ & $501.91 \pm 33.74$ \\
Average ParaCT $(\mu \mathrm{m})$ & $521.06 \pm 34.56$ \\
Average PeriCT $(\mu \mathrm{m})$ & $546.82 \pm 35.71$ \\
Corneal diameter $(\mathrm{mm})$ & $11.95 \pm 0.42$ \\
Average corneal curvature $(\mathrm{D})$ & $43.19 \pm 1.54$ \\
Axial ACD $(\mathrm{mm})$ & $3.43 \pm 0.24$ \\
Average AOD500 $(\mu \mathrm{m})$ & $552.51 \pm 110.68$ \\
Average TIA $\left(^{\circ}\right)$ & $36.68 \pm 4.65$ \\
\hline
\end{tabular}

$\mathrm{IOP}$, intraocular pressure; $\mathrm{CCT}$, central corneal thickness; $\mathrm{ACD}$, Anterior chamber depth; AOD500, Angle-opening distance taken at $500 \mu \mathrm{m}$; TIA, trabecular-iris angle; s.d., standard deviation.

$n=700$.

The unpruned and pruned regression tree models, with the decision rules, generated automatically by the CART method are shown in Figures 3 and 4, respectively. The first box in both regression tree models (Figures 3 and 4 ) is the root node which contains all cases $(n=700)$ and displays the mean dependent variable (IOP $=14.63 \mathrm{mmHg}$ ). The successive boxes in grey show the internal nodes which contain the different independent variables and their respective cut-off values. Each independent variable occupies a level with level one being more important than level two and so on. If the condition (independent variable and its respective cut-off value) is satisfied, the tree is followed along the left branch (shown as YES in the regression tree models). However, if the condition is not satisfied, the tree is followed along the right branch (shown as NO in the regression tree models).

Only 4 of the 11 independent variables were selected for inclusion in the unpruned regression tree model. The selected variables were, in order of decreasing importance, CCT, PeriCT, axial ACD and ParaCT (Figure 3). Crossvalidation was then used to prune this regression tree model to automatically generate an optimal-sized regression tree. The pruned regression tree model consisted of only three independent variables (CCT, PeriCT and axial ACD) omitting the ParaCT from the unpruned tree (Figure 3). There were 7 and 5 terminal branches in the unpruned and pruned regression tree models, respectively (Figures 3 and 4). In addition, any further splitting of the data set did not show any significant improvement in the regression tree model.

In both regression tree models (Figures 3 and 4), CCT was the most important independent variable with a cut-off value of $527 \mu \mathrm{m}$ as identified at level one. At level two, the PeriCT was identified as the next most important variable with cut-off values of $527 \mu \mathrm{m}$ and $625 \mu \mathrm{m}$ for CCT values that were $<527 \mu \mathrm{m}$ and $\geq 527 \mu \mathrm{m}$, respectively. In participants with CCT $\geq 527 \mu \mathrm{m}$ and PeriCT $<625 \mu \mathrm{m}$, the predicted IOP differed by $\sim 1.25 \mathrm{mmHg}$ depending on whether the axial ACD (level three) was $<3.58 \mathrm{~mm}$ or $\geq 3.58 \mathrm{~mm}$. The highest IOP $(19.36 \mathrm{mmHg}$ ) was found in 11 participants who had $\mathrm{CCT} \geq 527 \mu \mathrm{m}$ and PeriCT $\geq 625 \mu \mathrm{m}$. In the unpruned regression tree model (Figure 3 ), the lowest predicted IOP of $12.85 \mathrm{mmHg}$ was noted in participants $(n=119)$ with CCT and PeriCT $<527 \mu \mathrm{m}$ together with ParaCT $<488 \mu \mathrm{m}$. In the 


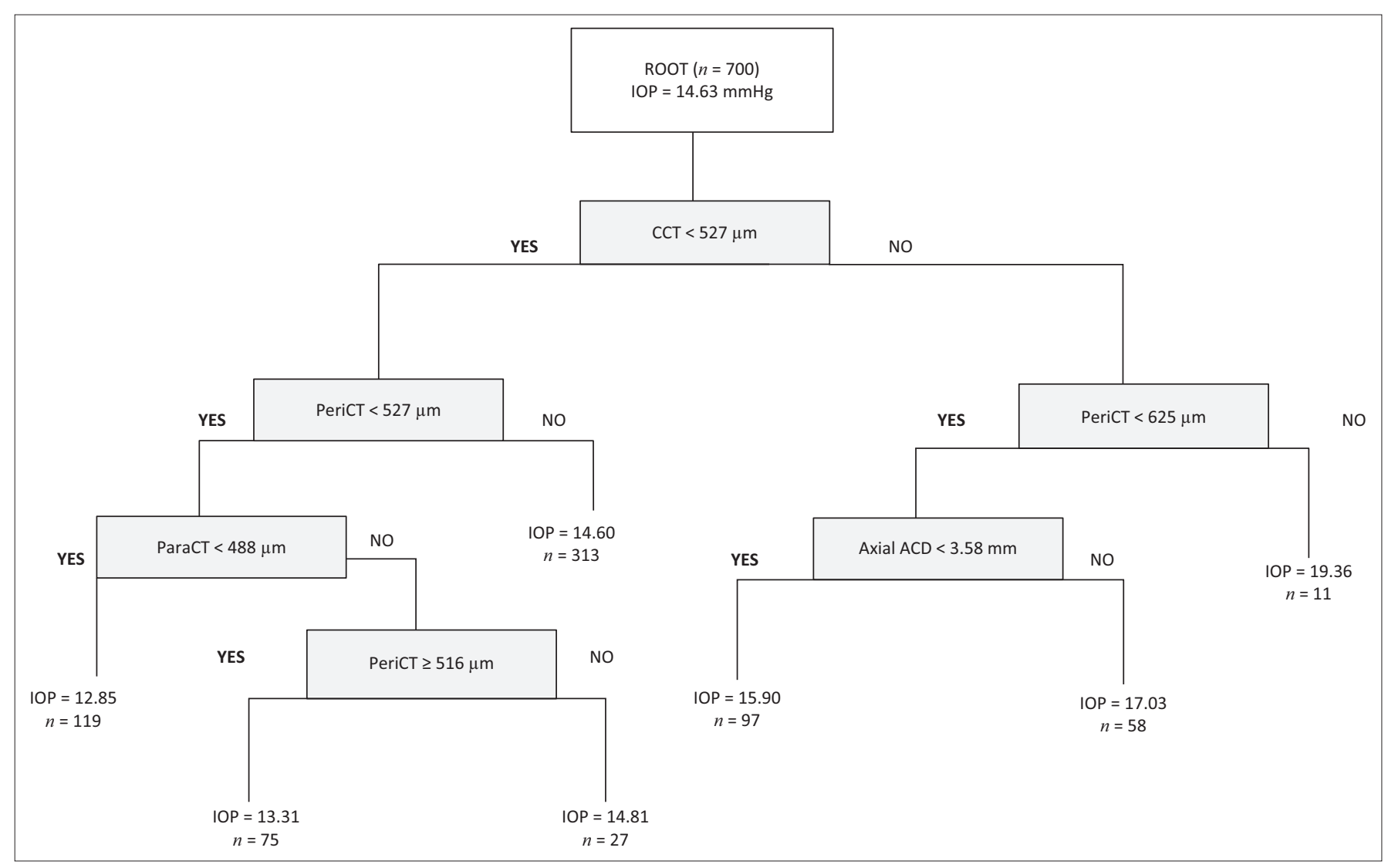

IOP, intraocular pressure; CCT, central corneal thickness; ACD, Anterior chamber depth.

FIGURE 3: Unpruned regression tree model, automatically generated by the classification and regression tree method, for prediction of intraocular pressure.

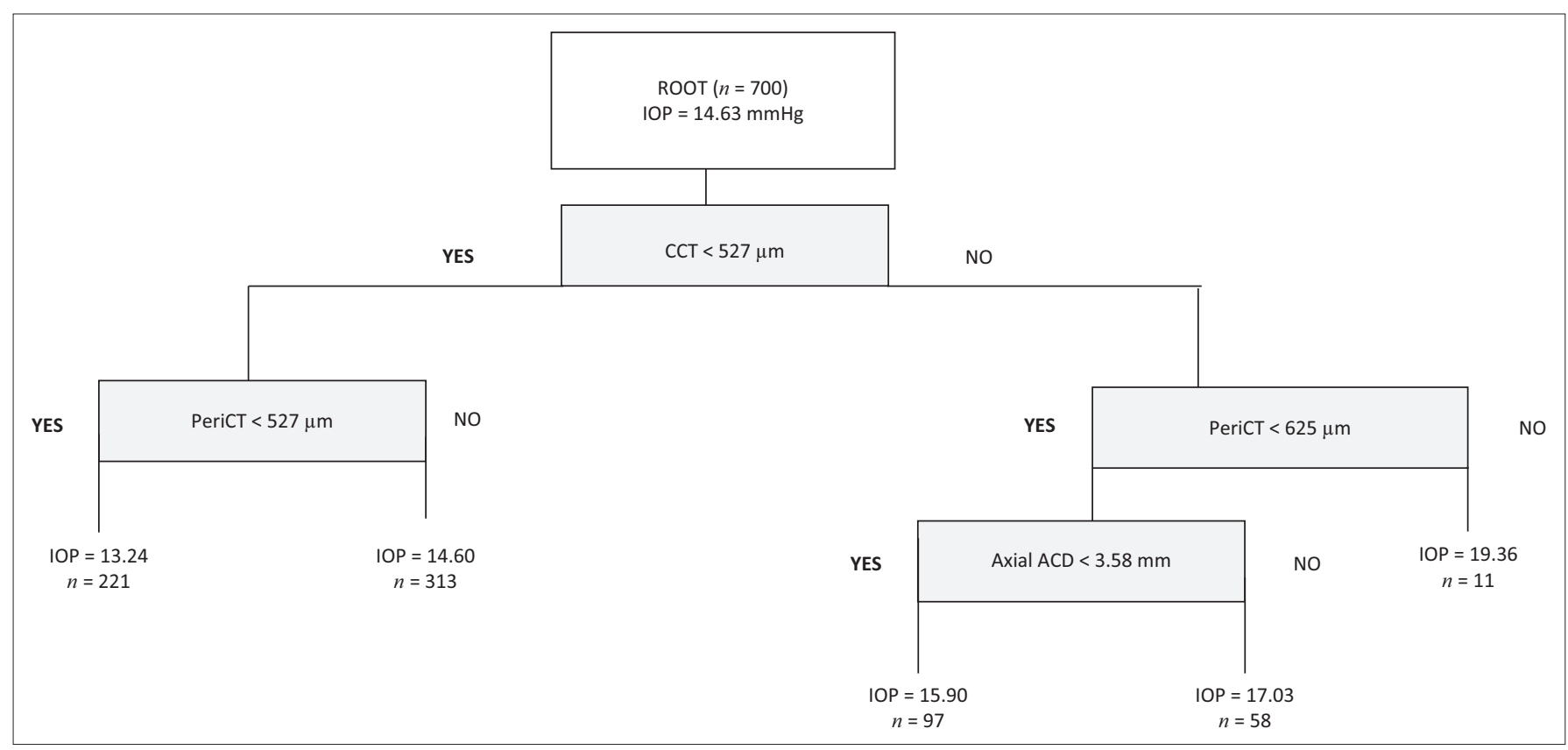

IOP, intraocular pressure; CCT, central corneal thickness; ACD, Anterior chamber depth.

FIGURE 4: Pruned regression tree model, automatically generated by the classification and regression tree method, for prediction of intraocular pressure.

pruned regression tree model (Figure 4), the majority of participants $(n=534)$ had CCT $<527 \mu \mathrm{m}$ and IOP measurements $<15 \mathrm{mmHg}$. The IOP was $13.24 \mathrm{mmHg}$ in 221 participants with both CCT and PeriCT $<527 \mu \mathrm{m}$. The IOP was $14.60 \mathrm{mmHg}$ in 313 participants who had CCT $<527 \mu \mathrm{m}$ but PeriCT $\geq 527 \mu \mathrm{m}$.

\section{Discussion}

The aim of this study was to identify which anterior segment ocular variables significantly influence IOP. Instead of solely using traditional statistical methods that require an a priori deliberate selection of which variables to analyse, from the 
researcher and/or statistician, the CART method was also used. This method is often used in data mining, makes no assumptions about the data and automatically selects the most important variables in a relationship or model. ${ }^{38,39}$ The results showed that four anterior segment variables influenced IOP. Three of these variables were measures of corneal thickness (CCT, PeriCT and ParaCT) while the other was the axial ACD.

Both regression tree models showed that CCT (at level one) was the most important anterior segment ocular variable that influenced IOP. This is not surprising as several studies have reported strong associations between IOP and CCT in normal individuals ${ }^{22,23,24}$ and individuals with glaucoma. ${ }^{67}$ Even though such associations have been reported consistently in the literature, the exact reason for this association is unclear. However, it could be a consequence of both IOP and CCT being measured at the corneal optical zone and the characteristics therein. For example, the corneal optical zone, which has a diameter of $4 \mathrm{~mm}$, is thought to have a uniform spherical curvature. ${ }^{68} \mathrm{~A}$ regular corneal surface is important because applanation tonometry measurements are estimated based on the force needed to applanate a certain area. ${ }^{69}$

A fixed area of flattening is especially important for Goldmann applanation tonometry because, at an applanation diameter of $3.06 \mathrm{~mm}$, the opposing effects of corneal rigidity and the surface tension of the tear film are cancelled out. ${ }^{69}$ Furthermore, the corneal optical zone has reduced thickness, ${ }^{70,71}$ is more compact and has lower mean collagen inter-fibrillar separations ${ }^{72}$ compared to the corneal periphery. These differences between the corneal optical zone and periphery could account for differences in resistance to applanation tonometry. ${ }^{73}$ It is speculated that these anatomical, physiological and topographical differences may also account for the association between IOP and CCT at the corneal optical zone. This explanation is reasonable because it has been shown that corneal biomechanical properties influence IOP. ${ }^{19,74}$ Furthermore, in this study the IOP measurements in the root node were split based on cutoff CCT value of $527 \mu \mathrm{m}$, which is similar to the theoretical calibrated CCT measurement $(520 \mu \mathrm{m})$ for Goldmann applanation tonometry. ${ }^{75}$

After CCT, the next important anterior segment variables were PeriCT, ParaCT and axial ACD. Corneal thickness beyond the central optical zone is not routinely measured in clinical practice. However, the results suggest that these corneal thicknesses may be important determinants of IOP. No studies could be found that investigated the relationship of IOP and corneal thickness measurements beyond the central optical zone (peripheral corneal thickness). The paucity of literature regarding IOP together with peripheral corneal thicknesses may relate to the fact that IOP is also not usually measured beyond the corneal optical zone. However, such measurements may be useful estimates of IOP, especially in instances of refractive surgeries, central corneal ulcers, epithelial oedema and high irregular astigmatism. ${ }^{73,76}$ Moreover, studies conducted on IOP measured at points beyond the corneal optical zone have reported reliable IOPs that are in agreement with IOPs measured at the central optical zone. ${ }^{73,76}$ The exact reason for the influence of peripheral corneal thicknesses on IOP is not readily explained. However, it may not be related to the thinnest corneal point being located at the corneal apex, as previously thought, but rather in the infero-temporal cornea. ${ }^{70,77}$ It is also likely that corneal rigidity will vary in relation to the different corneal thickness profiles and may also influence IOP..$^{19,74}$

In this study, the mean CCT recorded with the iVue100 OCT was $\sim 502 \mu \mathrm{m}$. Previous studies ${ }^{78,79}$ involving young South African adult samples, with similar demographic characteristics, have reported mean CCT measurements of $\sim 519 \mu \mathrm{m}$. Thus, mean CCT in this study was thinner when compared with other studies involving similar South African samples. This finding may be accounted for by using different instruments to measure CCT because this study used a device based on optical coherence tomography while previous studies ${ }^{78,79}$ used devices based on Scheimpflug photography. The overestimation of CCT measurements by Scheimpflug photography devices compared with optical coherence tomography devices have also been reported when CCT measurements were compared on the same study sample. ${ }^{71}$ The mean CCT in this study is also lower than the normal expected CCT measurement of $535 \mu \mathrm{m}$ reported by Doughty and Zaman ${ }^{80}$ in their meta-analysis. Thus, possible factors that may explain this discrepancy include differences in study design, instrumentation, sample size and ethnicity. ${ }^{80,81}$

The normal axial ACD is about $3 \mathrm{~mm}$ with a wide range of $2.6 \mathrm{~mm}-4.6 \mathrm{~mm} .{ }^{82}$ In this study, the mean axial ACD $(3.43 \mathrm{~mm})$ and axial ACD cut-off value $(3.58 \mathrm{~mm})$ in the regression tree models were within this expected range. Surprisingly, participants with axial ACDs deeper than the cut-off value had slightly higher IOPs $(\sim 1.25 \mathrm{mmHg})$. Tomoyose et al. $^{15}$ theorised that higher IOPs may not necessarily be associated with narrow anterior chambers when the ACA is open in normal individuals. In this study, axial ACD was selected as one of the important anterior segment ocular variables that influenced IOP. This finding is in contrast to previous studies, ${ }^{15,26}$ which report no association between IOP and ACD. This difference may be due to a cohort effect because studies that noted no association between IOP and ACD consisted of primarily older Japanese participants. ${ }^{15,26}$ It should be noted that Tomoyose et al. ${ }^{15}$ reported on axial ACD, while Kawase et al. ${ }^{26}$ reported on limbal ACD measurements.

In this study, the average AOD500 was $552.51 \mu \mathrm{m}$, which is similar to the calculated average AOD500 measurements by Cheon et al. ${ }^{83}(555.50 \mu \mathrm{m})$ and Leung et al. ${ }^{84}(549.50 \mu \mathrm{m})$. The average TIA was $36.68^{\circ}$, which is comparable with the mean TIA of $35.90^{\circ}$ reported in a sample of young German adults (mean age of 32.1 years) by Müller et al. ${ }^{55}$ when evaluated with another spectral-domain OCT. Despite also using a young adult sample (mean age of 25.93 years), Hosseini et al..$^{85}$ reported slightly higher mean TIA measurements $\left(39.36^{\circ}\right)$ when assessed with a Scheimpflug photography device. 
In this study, no ACA variables were selected by the CART model to influence IOP. Furthermore, IOP was not associated with average TIA, whereas there was only a weak association with average AOD500 $(r=0.09 ; p=0.016)$. These results are in agreement with previous studies that also reported no meaningful association in normal non-glaucomatous eyes between IOP and ACA variables. ${ }^{28,29}$ However, other studies $^{17,21}$ that used gonioscopy to evaluate ACA width have reported that IOP and ACA width are related. Although both these studies further commented that the associations found were marginal ${ }^{21}$ and would only result in small changes in IOP $\left(0.2 \mathrm{mmHg}\right.$ for every $10^{\circ}$ change in ACA width $) .{ }^{17}$

In this study, other corneal variables (excluding CCT which has been discussed above) have revealed interesting results regarding their relations with CCT, roles in the CART analysis and associations with IOP. Consistent with previous studies, ${ }^{70,71,77}$ corneal thickness increased significantly from the corneal centre towards the periphery. It is speculated that the normal thickening of the cornea towards the periphery is because of the increase in stromal collagen fibrils in the corneal periphery compared with the centre. ${ }^{86}$ Both corneal curvature and diameter were not selected by the CART method for inclusion in the regression tree models. This finding is consistent with the lack of strong associations seen between IOP and corneal curvature or diameter as has been reported in other studies. ${ }^{20,25,27}$

Despite an equal distribution of male and female participants in the study sample, gender was not detected as an important factor in the regression tree models. This finding is consistent with some studies that also reported that IOP is not affected by gender. ${ }^{8,18}$ Contradictory findings have been reported regarding IOP and age. Studies involving Asian individuals reported that IOP decreases with increasing age ${ }^{15,16,26}$ whereas other studies reported that IOP increases with increasing age. ${ }^{8,87}$ In this study, IOP was not affected by age, which may be attributed to the small range of participants' ages in this study in contrast to other studies that reported associations between IOP and age. $8,26,87$

The mean IOP in the general population ranges between $11 \mathrm{mmHg}$ and $21 \mathrm{mmHg} .{ }^{1}$ The mean IOP of $14.63 \mathrm{mmHg}$ in this study is almost identical to that reported by Sardiwalla et $a .^{78}$ Despite using a non-contact tonometer, Sardiwalla et al. ${ }^{78}$ also measured IOP in a young South African adult sample and reported a mean IOP of $14.6 \mathrm{mmHg} \pm 2.80$ $\mathrm{mmHg}$. In contrast, the mean IOPs reported in several older South African samples ${ }^{88,89}$ were smaller $(13.7 \mathrm{mmHg}$ $13.9 \mathrm{mmHg}$ ) than those found in this study, which may be attributed to the influence of age on IOP. ${ }^{15}$ This difference may also be related to differences in sample sizes wherein the studies with lower mean IOP measurements ${ }^{88,89}$ consisted of larger study samples. Because this study only included participants with IOPs $\leq 21 \mathrm{mmHg}$, all sub-groups of participants shown in the terminal nodes of the regression tree models (Figures 3 and 4 ) can be considered as variations of an essentially normal young South African adult population, although some eyes with IOP $\leq 21 \mathrm{mmHg}$ could have normal-tension or low-tension glaucoma. However, the age range in this study (17-30 years) probably excluded such instances. From the regression tree models, it can be seen that based on some anterior segment ocular variables, there is a wide range of normal IOP $(12.85 \mathrm{mmHg}-19.36 \mathrm{mmHg})$ in this young South African adult population.

Strengths of this study include the use of young South African adults consisting of an equal gender distribution with normal IOPs $(\leq 21 \mathrm{mmHg}$ ) and standardised data collection examination protocols. A Fourier-domain OCT was used in conjunction with inbuilt fixation targets to minimise measurement errors associated with off-centre fixation. In addition, this study used an interesting multivariate statistical method to determine which anterior segment variables significantly influenced IOP. Even though the CART method is able to split the data by only one independent variable at a time, ${ }^{41,43}$ this method still allowed the regression tree models to grow to 4 and 3 levels in the unpruned and pruned regression trees, respectively.

Possible limitations of this study include the narrow age range of participants and inclusion of participants with apparently normal IOP. This implies that the results of this study may not be generalised to older or younger South African individuals and those with IOP anomalies. Therefore, it is recommended that future studies include individuals with a wider age range and individuals with IOP anomalies to confirm if the same anterior segment variables influence IOP in such cases. Lastly, it is possible that other ocular variables and perhaps those of the posterior ocular segment such as posterior scleral rigidity and retinal nerve fibre layer thickness as well as axial length and refractive error might also influence IOP. Thus, it is recommended that future studies investigate the influence of posterior segment variables on IOP using the CART method as this may lead to an enhanced understanding of which ocular variables and their respective cut-off values influence IOP.

\section{Conclusion}

In this study an alternate way of evaluating the influence of anterior segment ocular variables on IOP is presented. Because IOP is an important consideration for glaucoma, understanding the relationship between anterior segment variables and IOP is important in screening for elevated IOP. Furthermore, there is a need to comprehend the critical factors that influence IOP in a simple to understand way in the context of clinical values instead of solely relying on correlation coefficients and $p$-values of significance. There are some important clinical implications that may be drawn from this study. Firstly, the regression tree models not only validate the profound influence CCT has on the IOP but also draw attention to the importance of corneal thickness measurements outside the corneal optical zone. The regression tree models further provide eye care clinicians with a realistic approximation of IOP based on the measurements of other anterior segment ocular variables. This information may help practitioners in 
detecting which patients require monitoring of IOP on the basis of other routinely measured anterior segment ocular variables.

\section{Acknowledgements}

The authors acknowledge Professor Murray from the University of KwaZulu-Natal for assistance with the statistical analysis for the study.

\section{Competing interests}

The authors declare that they have no financial or personal relationships that may have inappropriately influenced them in writing this article.

\section{Authors' contributions}

N.R. wrote the manuscript and R.H. provided feedback on the structure and content of the manuscript.

\section{References}

1. Kanski JJ. Clinical ophthalmology: A systematic approach. 6th ed. London: Butterworth-Heinemann, 2008; p. 374.

2. Pascolini D, Mariotti SP. Global estimates of visual impairment: $2010 . \mathrm{Br} J$ Ophthalmol. 2012;96:614-618. http://dx.doi.org/10.1136/bjophthalmol-2011300539

3. Quigley HA, Broman AT. The number of people with glaucoma worldwide in 2010 and 2020. Br J Ophthalmol. 2006;90:262-267. https://doi.org/10.1136/ bjo.2005.081224

4. Cesareo $M$, Ciuffoletti $E$, Ricci $F$, et al. Visual disability and quality of life in glaucoma patients. Prog Brain Res. 2015;221:359-374. https://doi.org/10.1016/ bs.pbr.2015.07.003

5. Quigley HA, Cassard SD, Gower EW, Ramulu PY, Jampel HD, Friedman DS. The cost of glaucoma care provided to medicare beneficiaries from 2002 to 2009 . Ophthalmology. 2013;120:2249-2257. https://doi.org/10.1016/j.ophtha.2013.04.027

6. Thomas R. Glaucoma in developing countries. Indian J Ophthalmol. 2012;60:446-450. https://doi.org/10.4103/0301-4738.100546

7. Quigley HA, Buhrmann RR, West SK, Isseme I, Scudder M, Oliva MS. Long term survey. Br J Ophthalmol. 2000;84:860-864. https://doi.org/10.1136/bjo.84.8.860

8. Hashemi $H$, Kashi AH, Fotouhi A, Mohammad K. Distribution of intraocular pressure in healthy Iranian individuals: The Tehran eye study. Br J Ophthalmol. 2005;89:652-657. https://doi.org/10.1136/bjo.2004.058057

9. Cook C, Foster P. Epidemiology of glaucoma: What's new? Can J Ophthalmol 2012;47:223-226. https://doi.org/10.1016/j.jcjo.2012.02.003

10. Gordon MO, Beiser JA, Brandt JD, et al. The ocular hypertension treatment study: Baseline factors that predict the onset of primary open-angle glaucoma. Arch Ophthalmol. 2002;120:714-720. https://doi.org/10.1001/archopht.120.6.714

11. Leske MC, Heijl A, Hyman L, Bengtsson B, Dong L, Yang Z. Predictors of long-term progression in the early manifest glaucoma trial. Ophthalmology. 2007;114:1965-1972. https://doi.org/10.1016/j.ophtha.2007.03.016

12. Nolan WP, Baasanhu J, Undraa A, Uranchimeg D, Ganzorig S, Johnson GJ. Screening for primary angle closure in Mongolia: A randomised controlled trial to determine whether screening and prophylactic treatment will reduce the incidence of primary angle closure glaucoma in an East Asian population. Br J Ophthalmol. primary angle closure glaucoma in an East Asian populatic
2003;87:271-274. https://doi.org/10.1136/bjo.87.3.271

13. Xu L, Fang W, Wang YX, Chen CX, Jonas JB. Anterior chamber depth and chamber angle and their associations with ocular and general parameters: The Beijing eye study. Am J Ophthalmol. 2008;145:929-936. https://doi.org/10.1016/j. ajo.2008.01.004

14. Devereux JG, Foster PJ, Baasanhu J, et al. Anterior chamber depth measurement as a screening tool for primary angle-closure glaucoma in an East Asian population. Arch Ophthalmol. 2000;118:257-263. https://doi.org/10.1001/archopht.118.2.257

15. Tomoyose E, Higa A, Sakai $H$, et al. Intraocular pressure and related systemic and ocular biometric factors in a population-based study in Japan: The Kumejima study. Am J Ophthalmol. 2010;150:279-286. https://doi.org/10.1016/j.ajo.2010. 03.009

16. Fukuoka S, Aihara M, Iwase A, Araie M. Intraocular pressure in an ophthalmologically normal Japanese population. Acta Ophthalmol. 2008;86:434-439. https://doi.org/10.1111/j.1600-0420.2007.01068.x

17. Foster PJ, Machin D, Wong TY, et al. Determinants of intraocular pressure and its association with glaucomatous optic neuropathy in Chinese Singaporeans: The Tanjong Pagar study. Invest Ophthalmol Vis Sci. 2003;44:3885-3891. https://doi. org/10.1167/iovs.03-0012
18. Iyamu E, Memeh $\mathrm{M}$. The association of central corneal thickness with intra-ocular pressure and refractive error in a Nigerian population. Online J Health Allied Sci. 2007;6:1-7.

19. Medeiros FA, Weinreb RN. Evaluation of the influence of corneal biomechanical properties on intraocular pressure measurements using the ocular response analyser. J Glaucoma. 2006;15:364-370. https://doi.org/10.1097/01.ijg.0000212268.42606.97

20. Kohlhaas M, Boehm AG, Spoerl E, Pürsten A, Grein HJ, Pillunat LE. Effect of central corneal thickness, corneal curvature, and axial length on applanation tonometry. Arch Ophthalmol. 2006;124:471-476. https://doi.org/10.1001/archopht.124.4.471

21. Jonas JB, Nangia V, Matin A, Sinha A, Kulkarni M, Bhojwani K. Intraocular pressure and associated factors: The central India eye and medical study. J Glaucoma. 2011;20:405-409. https://doi.org/10.1097/IJG.0b013e3181f7af9b

22. Suzuki S, Suzuki Y, Iwase A, Araie M. Corneal thickness in an ophthalmologically normal Japanese population. Ophthalmology. 2005;112:1327-1336. https://doi. org/10.1016/j.ophtha.2005.03.022

23. Nangia V, Jonas JB, Sinha A, Matin A, Kulkarni M. Central corneal thickness and its association with ocular and general parameters in Indians: The central India eye and medical study. Ophthalmology. 2010;117:705-710. https://doi.org/10.1016/j. ophtha.2009.09.003

24. Vijaya L, George R, Arvind $\mathrm{H}$, et al. Central corneal thickness in adult south Indians: The Chennai glaucoma study. Ophthalmology. 2010;117:700-704. https://doi. org/10.1016/j.ophtha.2009.09.025

25. Özcura F, Aydin S, Uzgören N. Effects of central corneal thickness, central corneal power, and axial length on intraocular pressure measurement assessed with Goldmann applanation tonometry. Jpn J Ophthalmol. 2008;52:353-356. https:// doi.org/10.1007/s10384-008-0535-9

26. Kawase K, Tomidokoro A, Araie M, Iwase A, Yamamoto T, Tajimi Study Group. Ocular and systemic factors related to intraocular pressure in Japanese adults: The Tajimi study. Br J Ophthalmol. 2008;92:1175-1179. https://doi.org/10.1136/ bjo.2007.128819

27. Iyamu E, Osuobeni E. Age, gender, corneal diameter corneal curvature and central corneal thickness in Nigerians with normal intra ocular pressure. J Optom. 2012;5:87-97. https://doi.org/10.1016/j.optom.2012.02.001

28. Amerasinghe N, Foster PJ, Wong TY, et al. Variation of angle parameters in Asians: Anterior segment optical coherence tomography study in a population of Singapore Malays. Invest Ophthalmol Vis Sci. 2009;50:2626-2631. https://doi. org/10.1167/iovs.08-2582

29. Rüfer F, Schröder A, Klettner A, Frimpong-Boateng A, Roider JB, Erb C. Anterior chamber depth and iridocorneal angle in healthy white subjects: Effects of age, gender and refraction. Acta Ophthalmol. 2010;88:885-890. https://doi. org/10.1111/j.1755-3768.2009.01588.x

30. Armstrong RA, Eperjesi F, Gilmartin B. The use of correlation and regression methods in optometry. Clin Exp Optom. 2005;88:81-88. https://doi. org/10.1111/j.1444-0938.2005.tb06672.x

31. Tu YK, Kellett M, Clerehugh V, Gilthorpe MS. Problems of correlations between explanatory variables in multiple regression analyses in the dental literature. $\mathrm{B}$ Dent J. 2005;199:457-461. https://doi.org/10.1038/sj.bdj.4812743

32. Mukaka MM. A guide to appropriate use of correlation coefficient in medical research. Malawi Med J. 2012;24:69-71.

33. Veličković VM. What everyone should know about statistical correlation. Am Sci. 2015;103:26-29. https://doi.org/10.1511/2015.112.26

34. Glynn R, Rosner B. Regression methods when the eye is the unit of analysis. Ophthalmic Epidemiol. 2012;19:159-165. https://doi.org/10.3109/09286586.20 12.674614

35. Armstrong RA. Statistical guidelines for the analysis of data obtained from one or both eyes. Ophthalmic Physiol Opt. 2013;33:7-14. https://doi.org/10.1111/ opo.12009

36. Bagley SC, White H, Golomb BA. Logistic regression in the medical literature: Standards for use and reporting, with particular attention to one medical domain. J Clin Epidemiol. 2001;54:979-985. https://doi.org/10.1016/S0895-4356(01)00372-9

37. Næs T, Mevik BH. Understanding the collinearity problem in regression and discriminant analysis. J Chemometr. 2001;15:413-426. https://doi.org/10.1002/ cem.676

38. Morgan J. Classification and regression tree analysis. Technical report No. 1. Boston: School of Public Health, Boston University; 2014.

39. Breiman L, Friedman J, Stone CJ, Olshen RA. Classification and regression trees. Belmont: Wadsworth International Group; 1984.

40. Moisen GG. Classification and regression trees. In: Jørgensen SE, Fath BD, editors. Encyclopedia of ecology. Oxford: Elsevier, 2008; p. 582-588.

41. Spreybroeck N. Classification and regression trees. Int J Public Health. 2012;57:243-246. https://doi.org/10.1007/s00038-011-0315-z

42. Lewis RJ. An introduction to classification and regression tree (CART) analysis Paper presented at: Annual Meeting of the Society for Academic Emergency Medicine; 2000 May 23; San Francisco, CA, 2000; p. 1-14.

43. Timofeev R. Classification and regression trees (CART): Theory and applications [homepage on the Internet]. Berlin: Humbolt University; 2004. Available from: http://edoc.hu-berlin.de/master/timofeev-roman-2004-12-20/PDF/timofeev.pdf

44. Loh WY. Classification and regression trees. Data Min Knowl Disc. 2011;1:14-23. http://dx.doi.org/10.1002/widm.8

45. Kurt I, Ture M, Kurum AT. Comparing performances of logistic regression, classification and regression tree, and neural networks for predicting coronary artery disease. Expert Syst Appl. 2008;34:366-374. https://doi.org/10.1016/j. eswa.2006.09.004 
46. Ito A, Hayashi M, Hamasaki T, Ebisu S. Risk assessment of dental caries by using classification and regression trees. J Dent. 2011:39:457-463. https://doi. org/10.1016/j.jdent.2011.04.002

47. Sato $\mathrm{R}$, Tomita $\mathrm{K}$, Sano $\mathrm{H}$, et al. The strategy for predicting future exacerbation of asthma using a combination of the asthma control test and lung function test. Asthma. 2009;46:677-682. https://doi.org/10.1080/02770900902972160

48. Mathers WD, Dongseok C. Cluster analysis of patients with ocular surface disease, blepharitis, and dry eye. Arch Ophthalmol. 2004;122:1700-1704. https://doi. org/10.1001/archopht.122.11.1700

49. Smadja D, Touboul D, Cohen A, et al. Detection of subclinical keratoconus using an automated decision tree classification. Am J Ophthalmol. 2013;156:237-246. https://doi.org/10.1016/j.ajo.2013.03.034

50. Fraser AS, Johnson AP, Wittich W, Overbury O. Critical success factors in awareness of and choice towards low vision rehabilitation. Ophthalmic Physiol Opt. 2015;35:81-89. https://doi.org/10.1111/opo.12169

51. Strobl C, Malley J, Tutz G. An introduction to recursive partitioning: Rationale application and characteristics of classification and regression trees, bagging and random forests. Psychol Methods. 2009;14:323-348. https://doi.org/10.1037/ a0016973

52. Optovue Inc. iVue 100 user's manual version 1.9. Fremont, CA: Optovue Inc.; 2011.

53. Wang D, Pekmezci M, Basham RP, He M, Seider MI, Lin SC. Comparison of different modes in optical coherence tomography and ultrasound biomicroscopy in anterior chamber angle assessment. J Glaucoma. 2009;18:472-478. https://doi. org/10.1097/IJG.0b013e31818fb41d

54. Quek DT, Narayanaswamy AK, Tun TA, et al. Comparison of two spectral domain optical coherence tomography devices for angle-closure assessment. Invest Ophthalmol Vis Sci. 2012;53:5131-5136. https://doi.org/10.1167/iovs.12 10132

55. Müller M, Dahmen G, Pörksen E, et al. Anterior chamber angle measurement with optical coherence tomography: Intraobserver and interobserver variability. J Cataract Refract Surg. 2006;32:1303-1308. https://doi.org/10.1016/j.jcrs.2006.07.014

56. Pavlin CJ, Harasiewicz K, Foster FS. Ultrasound biomicroscopy of anterior segment structures in normal and glaucomatous eyes. Am J Ophthalmol. 1992;113:381-389. https://doi.org/10.1016/S0002-9394(14)76159-8

57. Radhakrishnan S, Goldsmith J, Huang D, et al. Comparison of optical coherence tomography and ultrasound biomicroscopy for detection of narrow anterio chamber angles. Arch Ophthalmol. 2005;123:1053-1059. https://doi. org/10.1001/archopht.123.8.1053

58. Ramani KK, Mani B, Ronnie G, Joseph R, Lingam V. Gender variation in ocular biometry and ultrasound biomicroscopy of primary angle closure suspects and
normal eyes. J Glaucoma. 2007;16:122-128. https://doi.org/10.1097/01. normal eyes. J Glaucom

59. Li H, Leung CKS, Cheung CYL, et al. Repeatability and reproducibility of anterior chamber angle measurement with anterior segment optical coherence chamber angle measurement with anterior segment optical coherence
tomography. $\mathrm{Br}$ J Ophthalmol. 2007;91:1490-1492. https://doi.org/10.1136/ tomography. $\mathrm{Br}$

60. Mohamed S, Lee GKY, Rao SK, et al. Repeatability and reproducibility of pachymetric mapping with Visante anterior segment-optical coherence tomography. Invest Ophthalmol Vis Sci. 2007;48:5499-5504. https://doi.org/10.1167/iovs.07-0591

61. Li Y, Tang M, Zhang X, Salaroli CH, Ramos JL, Huang D. Pachymetric mapping with Fourier-domain optical coherence tomography. J Cataract Refract Surg. 2010;36:826-831. https://doi.org/10.1016/j.jcrs.2009.11.016

62. Radhakrishnan S, See J, Smith SD, et al. Reproducibility of anterior chamber angle measurements obtained with anterior segment optical coherence tomography. Invest Ophthalmol Vis Sci. 2007;48:3683-3688. https://doi.org/ $10.1167 /$ iovs.06-1120

63. Best N, Drury L, Wolffsohn JS. Clinical evaluation of the oculus keratograph. Con Lens Anterior Eye. 2012;35:171-174. https://doi.org/10.1016/j.clae.2012.04.002

64. Mao X, Savini G, Zhuo Z, et al. Repeatability, reproducibility, and agreement of corneal power measurements obtained with a new corneal topographer. Cataract Refract Surg. 2013;39:1561-1569. https://doi.org/10.1016/j. jcrs.2013.04.029

65. Yannakornpantana K. Comparison of the post-operative visual outcomes between contact technique and immersion technique in intraocular lens power calculation. Region 4-5 Med J. 2012;31:223-228.

66. Avitabile T, Longo A, Rocca D, Amato R, Gagliano C, Castaing M. The influence of refractive errors on IOP measurement by rebound tonometry (ICare) and Goldmann applanation tonometry. Graefes Arch Clin Exp Ophthalmol. Goldmann applanation tonometry. Graefes Arch Clin Exp
2010;248:585-591. https://doi.org/10.1007/s00417-009-1176-5

67. Gelaw $Y$. The impact of central corneal thickness on intraocular pressure among Ethiopian glaucoma patients: A cross sectional study. BMC Ophthalmology. 2012;12:1-6. https://doi.org/10.1186/1471-2415-12-58
68. Gupta AK, Krishna V. Corneal topography and wavefront sensing. In: Gupta AK Krishan V, editors. Clinical ophthalmology: Contemporary perspectives. 9th ed. Dehli: Elsevier, 2009; p. 3-20.

69. Fleming JB, Semes LP. Anterior segment evaluation. In: Benjamin WJ, editor. Borish's clinical refraction. 2nd ed. St. Louis, MO: Butterworth-Heinemann, 2006; p. 485-510.

70. Hashemi H, Asgari S, Mehravaran S, Emamian MH, Shariati M, Fotouhi A. The distribution of corneal thickness in a 40-to 64-year-old population of Shahroud, Iran. Cornea. 2011;30:1409-1413. https://doi.org/10.1097/ICO.0b013e31822018dd

71. Randleman JB, Lynn MJ, Perez-Straziota CE, Weissman HM, Kim SW. Comparison of central and peripheral corneal thickness measurements with scanning-slit, Scheimpflug and Fourier-domain ocular coherence tomography. Br J Ophthalmol. 2015;99:1176-1178. https://doi.org/10.1136/bjophthalmol-2014-306340

72. Boote C, Dennis S, Newton RH, Puri H, Meek KM. Collagen fibrils appear more closely packed in the prepupillary cornea: Optical and biomechanical implications. Invest Ophthalmol Vis Sci. 2003;44:2941-2948. https://doi.org/10.1167/iovs.03-0131

73. Queirós A, González-Méijome JM, Fernandes P, et al. Technical note: A comparison of central and peripheral intraocular pressure using rebound tonometry Ophthalmic Physiol Opt. 2007;27:506-511. https://doi.org/10.1111/j.1475-1313. 2007.00508.x

74. Liu J, Roberts CJ. Influence of corneal biomechanical properties on intraocular pressure measurement. J Cataract Refract Surg. 2005;31:146-155. https://doi. org/10.1016/j.jcrs.2004.09.031

75. Whitacre MM, Stein RA, Hassanein K. The effect of corneal thickness on applanation tonometry. Am J Ophthalmol. 1993;115:592-596. https://doi. applanation tonometry. Am J Oph
org/10.1016/S0002-9394(14)71455-2

76. Schipper I, Senn P, Oyo-Szerenyi K, Peter R. Central and peripheral pressure measurements with the Goldmann tonometer and Tono-Pen after photorefractive keratectomy for myopia. J Cataract Refract Surg. 2000;26:929-933. https://doi. org/10.1016/S0886-3350(99)00461-7

77. Hashemi H, Yazdani K, Mehravaran S, et al. Corneal thickness in a populationbased, cross-sectional study: The Tehran eye study. Cornea. 2009;28:395-400. https://doi.org/10.1097/ICO.0b013e31818c4d62

78. Sardiwalla Z, Moodley D, Ndawonde T, et al. A comparative study of central corneal thickness (CCT) and intraocular pressure (IOP) in University of KwaZuluNatal students of Black and Indian ethnicity. S Afr Optom. 2012;71:171-177. https://doi.org/10.4102/aveh.v71i4.83

79. Rampersad N, Mashige KP, Jhetam S. A comparison of intraocular pressure values obtained with the Tono-Pachymeter NT530P, iCare rebound tonometer and Goldmann applanation tonometer. S Afr Optom. 2011;70:109-116. https://doi. org/10.4102/aveh.v70i3.109

80. Doughty MJ, Zaman ML. Human corneal thickness and its impact on intraocular pressure measures: A review and meta-analysis approach. Surv Ophthalmol. 2000;44:367-408. https://doi.org/10.1016/S0039-6257(00)00110-7

81. Aghaian E, Choe JE, Lin S, Stamper RL. Central corneal thickness of Caucasians, Chinese, Hispanics, Filipinos, African Americans, and Japanese in a glaucoma clinic. Ophthalmology.2004;111:2211-2219. https://doi.org/10.1016/j.ophtha.2004.06.013

82. Barrett BT, McGraw PV. Clinical assessment of the anterior chamber depth. Ophthalmic Physiol Opt. 1998;18:32-39. https://doi.org/10.1016/S0275-5408(98)00031-3

83. Cheon $\mathrm{MH}$, Sung $\mathrm{KR}$, Choi EH, et al. Effect of age on anterior chamber angle configuration in Asians determined by anterior segment optical coherence
tomography; clinic-based study. Acta Ophthalmol. 2010;88:205-210. https://doi. org/10.1111/j.1755-3768.2010.01960.x

84. Leung $\mathrm{CK}$, Li H, Weinreb RN, et al. Anterior chamber angle measurement with anterior segment optical coherence tomography: A comparison between slit lamp OCT and Visante OCT. Invest Ophthalmol Vis Sci. 2008;49:3469-3474. https://doi. org/10.1167/iovs.07-1477

85. Hosseini SMA, Abolbashari F, Mohidin N. Anterior segment parameters in Indian young adults using the Pentacam. Int Ophthalmol. 2013;33:621-626. https://doi. org/10.1007/s10792-013-9747-1

86. Henriksson JT, Bron AJ, Bergmanson JPG. An explanation for the central to peripheral thickness variation in the mouse cornea. Clin Exp Ophthalmol. 2012;40:174-181. https://doi.org/10.1111/j.1442-9071.2011.02652.x

87. Leske MC, Connell AMS, Wu SY, Hyman L, Schachat AP. Distribution of intraocular pressure: The Barbados eye study. Arch Ophthalmol. 1997;115:1572-1576. https://doi.org/10.1001/archopht.1997.01100160221012

88. Rotchford AP, Johnson GJ. Glaucoma in Zulus: A population-based cross-sectional survey in a rural district in South Africa. Arch Ophthalmol. 2002;120:471-478. https://doi.org/10.1001/archopht.120.4.471

89. Rotchford AP, Kirwan JF, Muller MA, Johnson GJ, Roux P. Temba glaucoma study: A population-based cross-sectional survey in urban South Africa. Ophthalmology. 2003;110:376-382. https://doi.org/10.1016/S0161-6420(02)01568-3 